\title{
THE SURVEY OF THE BARRIERS TO NOT REPORTING MEDICATION ERRORS FROM THE PERSPECTIVE OF NURSING STUDENTS
}

\author{
ZAHRA POURNAMDAR ${ }^{1}$, SADEGH ZARE ${ }^{2 *}$, ALIREZA SHAMELI ${ }^{2}$, HOSSEIN JAFARI ${ }^{2}$
}

${ }^{1}$ Department of Nursing, Community Nursing Research Center, Pregnancy Health Research Center, Zahedan University of Medical Sciences, Zahedan, Iran. ${ }^{2}$ Department of Nursing, Student Scientific Research Center, Zahedan University of Medical Sciences, Zahedan, Iran. Email: zaresadegh93@yahoo.com

Received: 10 April 2016, Revised and Accepted: 30 June 2016

\section{ABSTRACT}

Objective: Reporting the medication errors, on the one hand, causes the preservation and observation of the patient security, and on the other hand, it is regarded as a valuable information treasure in line with the prevention of the medication errors expression in the future. Therefore, the present study has been conducted with the objective of the survey of barriers to medication errors reporting from the perspective of the nursing students.

Methods: This study is a descriptive research which has been conducted on 87 nursing students who have been selected based on a random method. To gather the required information, there has been made use of a two-part questionnaire, the first part of which deals with the study of the demographic characteristics and the second part pertains to the factors influencing not reporting the medication errors. In the end, after the necessary information collected the data were analyzed by taking advantage of SPSS 19 and descriptive statistics.

Results: The individuals average age in the present study was $21.09 \pm 2.48,51$ individuals were female. 24 individuals were studied in semester 4,31 people were passing term 6 , and 32 individuals were in term 8 . The highest mean score as obtained in managerial aspect. In addition, the highest mean score was related to the items "concentration of the managers solely on the person who has made the mistake and disregarding of the other factors involved in mediation error" and "lack of receiving a positive feedback from the nursing supervisors following reporting the medication error" and the lowest mean score was related to the item "not being considerate to some of the medication errors reporting."

Conclusion: The results of this study indicated that the highest mean score for not reporting the medication errors went to the managerial dimensions Therefore, the supervisors and the nursing staff should be cautioned regarding their behavior, regarding the medication errors reporting, and consider the problems and issues systematically.

Keywords: Medication error, University students, Zahedan, Nursing.

(C) 2016 The Authors. Published by Innovare Academic Sciences Pvt Ltd. This is an open access article under the CC BY license (http://creativecommons. org/licenses/by/4.0/) DOI: http://dx.doi.org/10.22159/ajpcr.2016.v9s2.13414

\section{INTRODUCTION}

The rapid changes in the medical-health systems have confronted the medical professional personnel with numerous ethical and medical dimensions [1,2]. During the past years, the focus has been on the diagnosis and prevention of the medication errors regarding the patient's security management [3]. From the 1990s, most of the studies formed in line with the peripheral factor recognition, which can play a significant role in the error occurrence and consequently, the likely lack of not reporting such errors [4]. Medication errors are considered a global problem and can lead to serious injuries and even the patient death. Medication errors have been classified among the five classes of substantial medical errors by the American Institute of Medical Sciences [5]. Medication errors have been defined as the inappropriate use or application of drugs which is preventable and the most common nursing medication errors include forgetting to administer one or several classes of drugs to the patient, giving drugs without the physician's prescription, wrong dosage, wrong method, wrong time, wrong form, mistake in preparing the right dosage, and wrong prescription technique which can potentially or interactively cause damage or injury to the patient [6-8]. The process of administering drugs to the patients is one of the most important and most fundamental responsibilities on the shoulder of the nurses and doing it neatly and appropriately can play a significant role in patient's security [9]. Generally speaking, medication error in hospitals is an old problem, and it is considered as one of the most common events in the nursing profession [4]. In a retrospective analysis study of 496 deaths resulting from medication errors performed during the years from 1993 to 1998, human factor was responsible in $65.2 \%$ of the cases. Washington national sciences university health institution alerted in a book that one million medication errors occur annually [10]. On the other hand, the occurrence of the medication errors brings about distrust followed by patients' dissatisfaction and lead to stress and ethical conflicts on the nurses' part [11]. Nowadays, more than 20 thousand drugs are available around the world in case of improper use of which cause injuries to the patients and can be dangerous [12] Since mediation errors are among the most common events occurring in the nursing profession, the primary, and natural outcome of such errors are the lengthening of the patients' stay in the hospitals and also the increase in the costs which occasionally can result in severe injuries and even patient's death [13]. Pointing to the prevalence and the dangerous nature of the medication errors to the patients, it is regarded as the patient safety index $[14,15]$. Unlike the great prospects coming from medication errors reporting and the ethical issues related to it, the nurses may be doubtful and postpone revealing the medication error for the patient due to the reasons such as protecting themselves from punishment or managerial regulations [16].

In addition, the main reasons for not reporting the medication errors have been classified in the form of individual and organizational factors. Being fearful is one of the main individual barriers to not reporting the medication errors in nurses, fear of being reproached and reprimanded by the managers, peers reactions and fear of sin, and statutory complaints by the patients has been cited among the factors behind not reporting the medication errors [17]. The studies have shown that approximately one-third of the medication errors is preventable, and one can reach to this conclusion that all of the medication errors are preventable $[7,15]$. One way to avoid medication error occurrence is to encourage the staff to report their mistakes and errors to be able to think of policies and strategies and eliminate factors influencing 
medication errors reporting, and consequently, they would not be reoccurred [9]. Reporting the medication errors, on the one hand, bring about the protection and preservation of the patient's safety and on the other hand, these reports can be compiled and be regarded as a valuable information bank that can be used for avoiding the future medication errors [18]. Therefore, the present study aims of the survey of the factors and barriers to not reporting the medication errors from the perspectives of the nursing students.

\section{METHODS}

This study is a descriptive research which has been conducted on 87 nursing students, all of whom have been selected randomly in 2016 To gather the information required for the study, there has been made use of a two-part questionnaire the first part of which deals with the demographic characteristics (age, gender, and curriculum semester) and the second part pertained to the factors influencing the barriers to reporting medication errors which included 19 items and in three areas including fear of reporting outcomes (11 items), factors relating to the reporting process ( 3 items), and managerial factors ( 5 items). The items were scored based on Likert's five-point scale from "completely agree" (Score 5) to "completely disagree" (Score 1). In the next step, each question and each areas score were calculated. The questionnaire content validity was confirmed in the study performed by Heydari et al. [9], the reliability obtained according to Cronbach's alpha method was 0.86 .

To collect the data, after acquiring a confirmation letter from Zahedan Medical Sciences University research vice chancellorship and obtaining a letter of recommendation, the researcher attended the nursing and obstetrician department and after coordination with the department educational vice chancellorship; first, the study objectives were explained to the students and after acquiring an oral consent the questionnaire was distributed in sufficient number in each of the curriculum terms and semesters. Of course, the questionnaires were administered to term-8 students in hospital due to not having theoretical classes in the college. At the beginning of the questionnaires, there was a written text to inform the participants of their consent for responding to the questionnaire which read "your cooperation in responding to the questions means that you are consciously aware of the participation in the questionnaire. In addition, the information provided by you in the questionnaire is confidential, and you are not exposed to any harm." After the questionnaires were completed, they were collected and reviewed by the researcher and the deficit ones were again returned to the participants to be completed and the students were asked to complete the related parts. Finally, after collecting the questionnaires, the data were analyzed by taking advantage of SPSS 19 and descriptive statistics.

\section{RESULTS}

The participants average age was $21.09 \pm 2.48,51$ individuals $(58.6 \%)$ were women. 24 individuals $(27.6 \%)$ were studied in term 4,31 individuals $(35.6 \%)$ in term 6 , and 32 individuals $(36.8 \%)$ in term 8 . The highest score was obtained for the managerial dimension. In addition, the highest mean score regarding the items was belonged to the item "managers' sole concentration on the responsible person and their ignorance of the other factors involved in the error occurrence" and "the lack of positive feedback from the nursing supervisors side following the error reporting" and the lowest mean score pertained to the item "not caring for some of the medication errors reporting."

Frequency, mean, and standard deviation of the questionnaire items related to the barriers to the medication errors reporting from the university students' point of view have been provided in Table 1 .

\section{DISCUSSIONS}

In the present study, the highest mean score belonged to the managerial dimension. The findings of the study obtained by Heydari which was conducted in Lorestan training hospital indicated that $91.6 \%$ of the considered fear of the managers' reaction as the main barrier to medication error reporting [19]. Also, the highest items score mean was related to the item "concentration of the managers and officials on the responsible person and ignoring all of the factors involved" and "not receiving positive feedback from the nursing supervisors' side following reporting". In the study performed by Musa Rezaee et al among the most common barriers to reporting the medication errors from the nursing students point of view were the lack of a system for recording such errors (84\%), not being aware of the exact definition of the medication errors (81\%), fear of suing and judicial issues (80\%), time consuming nature of the reporting process (73\%) and not being sufficiently supported by the system (68\%) [20]. Findings by Wakefield et al [21] and Uribe et al [22] also were indicative of the time consuming nature of the error recording process and the lack of awareness and a general consensus regarding the medication error definition as the barriers to reporting medication errors. On the other hand, some of the studies indicated the time consuming nature of error recording process and establishing relationship with the medical team in this respect as the barriers to reporting medication error [21, 22]. But, in a study performed by Hesari et al they came to this conclusion that the highest percent of not reporting the medication errors by nurses is in relation to the managerial factors which involves the managers and officials concentration on the responsible individual and ignorance of the other effective factors which conforms with the results obtained in the present study [23]. These reasons are indicative of the concentration of the managers on the individual in lieu of concentrating on the error and the factors leading to the error. While medication errors occur in one of the stages in drug administration, therefore they should be regarded as systemic errors and they should never be considered among the human offences with statutory aspects deserving occupational punishment and their investigation and evaluation should be conducted with the purpose of warning and prevention and avoidance of the reiteration of such errors [25]. It seems that the officials and nursing staff should be cautioned about their treating style of the medication errors and they should know that such errors should be handled systematically. Emphasizing the identification of the culprit and reprimanding him or her does not appear to solve any problem rather it can mask the future mistakes and result in a deficient cycle in reporting medication errors, reoccurrence of the errors and cause disruptions and disorders in patient's treatment protocol.

The studies conducted in the Western countries are suggestive of the fact that such errors are increasing, but in our country due to the shortage of human workforce in comparison to the health-care service standard, the imprecise supervision on the medication process, and the absence of a definite and correct error reporting system the rate of such reports is not announced exactly [24]. Health-care system inadequacies play a more significant role than the human workforce mistakes in medication errors. Pape et al. assert that changing the labor rules, strong and powerful management, and the increase in the number of the workforce brings about the nursing safety and service quality enhancements [25].

According to the aforementioned subjects, the managers and the authorities should adopt an appropriate method and pattern of treating and handling the staff regarding the improvement of the situation and determination of the rate of the medication errors instead of showing improper behaviors the result of which would be presentation of more straightforward and clearer reports [23], because medication errors reporting process would be capable of reoccurrence of such errors by the other individuals. In addition, there can be made use of an anonymous error recording system to reduce the treatment and nursing personnel fears and also to reduce the heavy load of taking medication error responsibility and enhancing the error reporting process [26].

One of the main limitations and constraints in the present study was that this study was performed in a specific time span. Secondarily, the information required for this study was obtained via questionnaire. And because, the study was of a questionnaire administration nature; therefore, it can be claimed that such a method of data gathering could have influenced the results. To put it differently, there was this 
Table 1: Frequency, mean, and standard deviation for the questionnaire items related to the barriers to the medication errors reporting from the university students' point of view

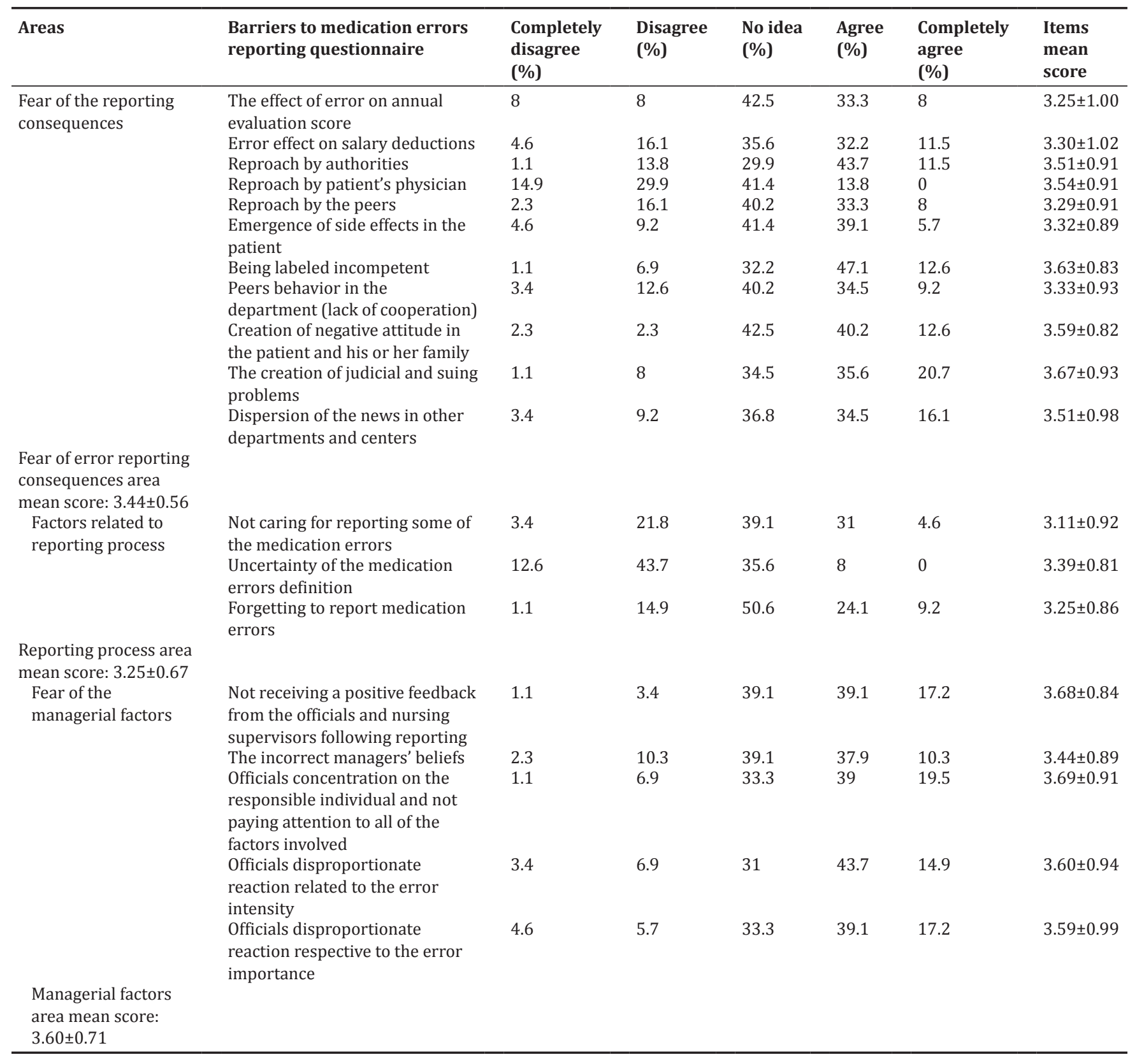

possibility that some of the individual and organizational limitations and barriers may have caused the individuals to avoid completing the questionnaires correctly or they may have refrained to complete the questionnaires with perfect and due concentration.

\section{CONCLUSIONS}

The results obtained in this study indicated that the highest mean score for the barriers of not reporting the medication errors was pertained to the managerial aspect. Therefore, the authorities and nursing officials should be informed regarding their method of treating and handling such medication errors and approach the problem from a systematic point of view.

\section{ACKNOWLEDGMENT}

This study was the result of a student research project approved at Zahedan University of Medical Sciences. Hereby, we express our deep gratitude to those people who participated and collaborated in this study and Research authorities of Zahedan University of Medical Sciences who helped us in the process of data collection and financial support.

\section{REFERENCES}

1. Jahantigh M, Zare S, Shahrakipour M. The survey of the relationship between ethical climate and ethical behavior in nurses. Der Pharm Lett 2016;8(3):189-93.

2. Miandoab NY, Shahrakipour M, Zare S. The study of relationship between the ethical climate and job interestedness. Der Pharm Lett 2016;8(3):86-90.

3. Gorgich EA, Barfroshan S, Ghoreishi G, Yaghoobi M. Investigating the causes of medication errors and strategies to prevention of them from nurses and nursing student viewpoint. Glob J Health Sci 2015;8(8):54448.

4. Anderson DJ, Webster CS. A systems approach to the reduction of medication error on the hospital ward. J Adv Nurs 2001;35(1):34-41. 
5. Mrayyan MT, Shishani K, Al-Faouri I. Rate, causes and reporting of medication errors in Jordan: Nurses' perspectives. J Nurs Manag 2007;15(6):659-70.

6. Hansen RA, Greene SB, Williams CE, Blalock SJ, Crook KD, Akers R, et al. Types of medication errors in North Carolina nursing homes: A target for quality improvement. Am J Geriatr Pharmacother 2006;4(1):52-61.

7. Hughes RG, Ortiz E. Medication errors: Why they happen, and how they can be prevented. J Infus Nurs 2005;28 2 Suppl:14-24.

8. Lehmann CU, Conner KG, Cox JM. Preventing provider errors: Online total parenteral nutrition calculator. Pediatrics 2004;113(4):748-53.

9. Hosseinzadeh M, Aghajari PE, Mahdavi N. Reasons of nurses medication errors and persepectives of nurses on barriers of error reporting. Hayat 2012;18(2):66-75.

10. Nikpeyma N, Gholamnejad H. Reasons for medication errors in nurses veiws. J Shahid Beheshti Sch Nurs Midwifery 2009;19(64):18-24.

11. Jolaee S, Hajibabaee F, Peyravi H, Haghani H. Nursing medication errors and its relationship with work condition in Iran University of Medical Sciences. Iran J Med Ethics Hist Med 2009;3(1):65-76.

12. Young $H$. Lack of pharmacological training causes overuse and misuse of drugs. CMAJ 2008;178(3):276.

13. Webster CS, Anderson DJ. A practical guide to the implementation of an effective incident reporting scheme to reduce medication error on the hospital ward. Int J Nurs Pract 2002;8(4):176-83.

14. Hume M. Changing hospital culture and systems reduces drug errors and adverse events. Qual Lett Healthc Lead 1999;11(3):2-9.

15. Stratton KM, Blegen MA, Pepper G, Vaughn T. Reporting of medication errors by pediatric nurses. J Pediatr Nurs 2004;19(6):385-92.

16. Nejad IM, Hojjati H, Sharifniya SH, Ehsani SR. Evaluation of medication error in nursing students in four educational hospitals in Tehran. Iran J Med Ethics Hist Med 2010;3:60-9.

17. Alijanzadeh M, Mohebifar R, Azadmanesh Y, Faraji M. The frequency of medication errors and factors influencing the lack of reporting medication errors in nursing at teaching hospital of Qazvin University of Medical Sciences, 2012. J Health 2015;6(2):169-79.

18. Chiang HY, Pepper GA. Barriers to nurses' reporting of medication administration errors in Taiwan. J Nurs Scholarsh 2006;38(4):392-9.

19. Heydari H, Kamran A, Pirzadeh A. Assessment of nurses perceived barriers and behaviors and behaviors to reporting medication errors in hospitals of Lorestan University of Medical Sciences. Iran Health Syst Res 2012;8:806-13.

20. Musarezaie A, Irajpoor A, Abdoli S, Ahmadi M, Ghasemi TM. How do wedecline the medicinal errors and refusal in reporting medication errors in nurses in critical coronary unit? An action-research study. J Health Syst Res 2013;9(6):594-604.

21. Wakefield DS, Wakefield BJ, Uden-Holman T, Borders T, Blegen M, Vaughn T. Understanding why medication administration errors may not be reported. Am J Med Qual 1999;14(2):81-8

22. Uribe CL, Schweikhart SB, Pathak DS, Dow M, Marsh GB. Perceived barriers to medical-error reporting: An exploratory investigation. J Healthc Manage 2002;47(4):263-79.

23. Hesari B, Ghodsi H, Hoseinabadi M, Chenarani H, Ghodsi A. A survey of nurses' perceptions of the causes of medication errors and barriers to reporting in hospitals affiliated to Neyshabur University of Medical Sciences. Iran J Kerman Univ Med Sci 2015;22(1):105-11.

24. Mohammadnejad E, Ehsani KK, Salari A, Sajjadi A, Hajiesmaeelpour A Refusal in reporting medication errors from the perspective of nurses in emergency ward. J Res Dev Nurs Midwifery 2013;16(10):61-8.

25. Pape TM, Guerra DM, Muzquiz M, Bryant JB, Ingram $M$, Schranner B, et al. Innovative approaches to reducing nurses' distractions during medication administration. J Contin Educ Nurs 2005;36(3):108-16

26. Elder NC, Graham D, Brandt E, Hickner J. Barriers and motivators for making error reports from family medicine offices: A report from the American academy of family physicians National research network (AAFP NRN). J Am Board Fam Med 2007;20(2):115-23 